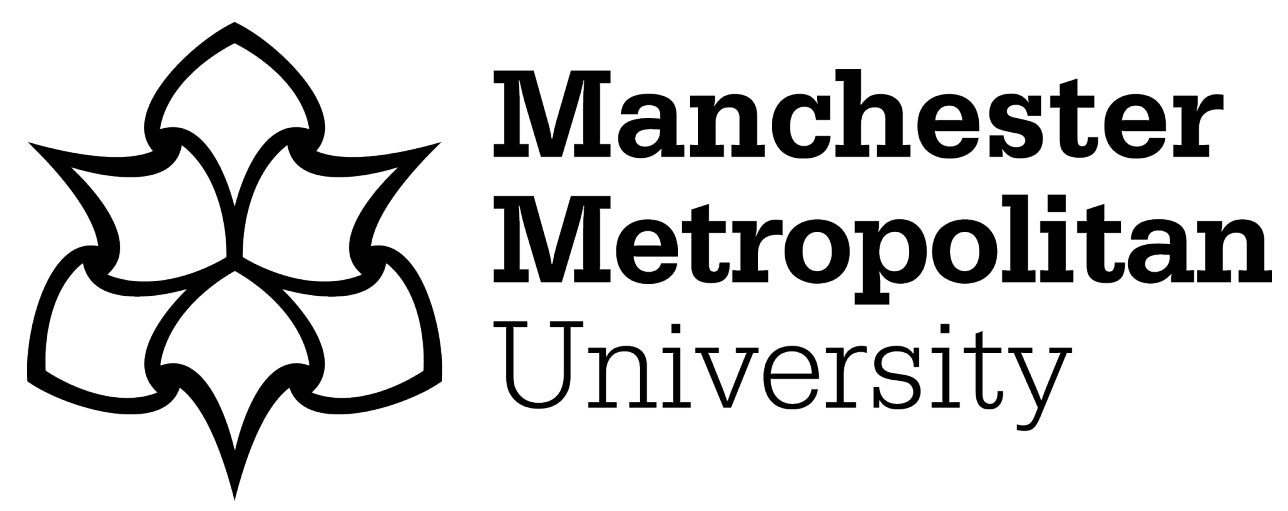

Regmi, YN ORCID logoORCID: https://orcid.org/0000-0001-6588-7683, Wan, C, Duffee, KD and Leonard, BM (2015) Nanocrystalline Mo2C as a Bifunctional Water Splitting Electrocatalyst. ChemCatChem, 7 (23). pp. 39113915. ISSN 1867-3880

Downloaded from: https://e-space.mmu.ac.uk/624769/

Version: Accepted Version

Publisher: Wiley

DOI: https://doi.org/10.1002/cctc.201500677

Please cite the published version 


\title{
Electrocatalytic Activity and Stability Enhancement through Preferential Deposition of Phosphide on Carbide
}

\author{
Yagya N. Regmi ${ }^{+},{ }^{[a]}$ Asa Roy ${ }^{+[b, c]}$ Gabriel A. Goenaga, ${ }^{[d]}$ James R. McBride ${ }^{[e]}$ B. R. Rogers, ${ }^{[f]}$ \\ Thomas A. Zawodzinski, Jr., ${ }^{[c, d]}$ Nicole Labbé, ${ }^{[a]}$ and Stephen C. Chmely*[a]
}

口Please provide first name for Dr. Rogers $\square$ Phosphides and carbides are among the most promising families of materials based on earth-abundant elements for renewable energy conversion and storage technologies such as electrochemical water splitting, batteries, and capacitors. Nickel phosphide and molybdenum carbide in particular have been extensively investigated for electrochemical water splitting. However, a composite of the two compounds has not been explored. Here, we demonstrate selective deposition of nickel phosphide on mo- lybdenum carbide in the presence of carbon by using a hydrothermal synthesis method. We employ the hydrogen evolution reaction in acid and base to analyze the catalytic activity of phosphide-deposited carbide. The composite material also shows superior electrochemical stability in comparison to unsupported phosphide. We anticipate that the enhanced electrochemical activity and stability of carbide deposited with phosphide will stimulate investigations into the preparation of other carbide-phosphide composite materials.

\section{Introduction}

Recent years have seen a tremendous surge in the development of materials based upon earth-abundant elements that can efficiently catalyze electrochemical water splitting. Cost-effective and scalable alternatives to Pt-, Ru-, and Ir-based catalysts are critical to generate $\mathrm{H}_{2}$ in affordable and abundant quantities. ${ }^{[1]}$ Carbides and phosphides of early transition metals are among the most promising noble-metal-free electrocata-

[a] Dr. Y. N. Regmi, ${ }^{+}$Dr. N. Labbé, Dr. S. C. Chmely

Center for Renewable Carbon

University of Tennessee

Knoxville, Tennessee 37996 (USA)

E-mail:yregmi@utk.edu schmely@utk.edu

[b] A. Roy

Bredesen Center for Interdisciplinary Research and Education

Knoxville, Tennessee 37996 (USA)

[c] A. Roy, ${ }^{+}$Dr. T. A. Zawodzinski, Jr.

Oak Ridge National Laboratory

Oak Ridge, Tennessee, 37831 (USA)

[d] Dr. G. A. Goenaga, Dr. T. A. Zawodzinski, Jr.

Department of Chemical and Biomolecular Engineering

University of Tennessee

Knoxville, Tennessee 37996 (USA)

[e] Dr. J. R. McBride

Department of Chemistry and Vanderbilt Institute of Nanoscale Science and Engineering

Vanderbilt University

Nashville, Tennessee 37240 (USA)

[f] Dr. B. R. Rogers

Chemical and Biomolecular Engineering

Vanderbilt University

Nashville, TN 37235 (USA)

$\left.{ }^{+}\right]$These authors contributed equally to this work.

$\square$ Supporting information and the ORCID identification number(s) for the

(iD author(s) of this article can be found under http://dx.doi.org/10.1002/ cctc. 201601477. lysts and have been investigated for hydrogen evolution reaction (HER) and oxygen evolution reaction (OER) in acidic, basic, and neutral environments. ${ }^{[2]}$ The overpotentials required to generate the widely accepted benchmark activity of $10 \mathrm{mAcm}^{-2}$ have approached within $50 \mathrm{mV}$ of $\mathrm{Pt} / \mathrm{C}$ for HER and $\mathrm{IrO}_{2}$ for OER. ${ }^{[3]}$ Strategies such as synthesis of polymorphs and crystalline species, engineering extremely small and dispersed carbide and phosphide particles to populate catalytically active sites on the surface, supporting or caging nanoparticles on high surface area substrates, and formation of composite materials including core-shell structures have led to the reduction in overpotentials and improved stabilities. ${ }^{[4]}$

Nickel phosphide, molybdenum phosphide, and molybdenum carbide are among the most promising non-noble-metalbased electrocatalysts for water splitting. Although nickel carbide tends to be unstable under electrocatalytic conditions, a recent report by Fan et al. has indicated that the activity and stability of $\mathrm{Ni}_{3} \mathrm{C}$ can be improved by encasing the carbide in graphene. ${ }^{[5]}$ Several strategies have been reported over the years for preparing bimetallic catalysts comprised of $\mathrm{Ni}$ and Mo, and these have been investigated for a variety of reactions. ${ }^{[6]} \mathrm{Ni}_{3} \mathrm{Mo}_{3} \mathrm{C}$ showed improved activity over $\mathrm{Mo}_{2} \mathrm{C}$ if used as an anode material in fuel cells, but nickel molybdenum carbides as hydrogen evolution catalysts with comparable activities to that of $\mathrm{Mo}_{2} \mathrm{C}$ have not been reported. ${ }^{[7]}$ Bimetallic nickel molybdenum phosphide with comparable activity to that of either nickel or molybdenum phosphide as a water splitting catalyst has also not been reported to the best of our knowledge. Most of the successful strategies for Ni- and Mo-based bimetallic electrocatalysts have instead been invested in either forming composites or doping. ${ }^{[8]}$

Hexagonal molybdenum carbide in particular has been seen as an effective host system for doping and a superior catalyst 
support. Previously, Leonard and co-workers have reported that carbides show enhanced mass-normalized activities of $\mathrm{Pt}$ in comparison with carbon if used as catalyst supports, and molybdenum carbide had the highest enhancement in normalized electrocatalytic activities among the transition metal carbides investigated. ${ }^{[9]}$ Further, the same group demonstrated that the $\mathrm{Fe}_{2} \mathrm{~N}$-type hexagonal structure $\left(\beta-\mathrm{Mo}_{2} \mathrm{C}\right)$ is the most active HER catalyst among various molybdenum carbide crystal phases. ${ }^{[10]}$ Additionally, if hexagonal molybdenum carbide was templated on multiwalled carbon nanotubes (MWCNT), the electrocatalytic activity was significantly enhanced. ${ }^{[11]}$ Nanostructured hexagonal $\mathrm{Fe}_{2} \mathrm{P}$-type nickel phosphide $\left(\mathrm{Ni}_{2} \mathrm{P}\right)$ has one of the lowest HER overpotentials among non-noble transition metal compounds. ${ }^{[12]}$ Nickel phosphide of various stoichiometries and crystal structures can be prepared by variation of the metal precursor and reaction conditions by using a facile hydrothermal synthesis method. ${ }^{[13]}$ Moreover, numerous reports detail the preparation of bimetallic alloys of nickel and molybdenum by using a hydrothermal synthesis method that employs metal salts as precursors. ${ }^{[14]}$ Wang and co-workers recently reported that molybdenum sulfide can be prepared on a molybdenum carbide surface by using a hydrothermal synthesis method without any significant changes in the structure of the carbide itself. ${ }^{[15]}$ The composite material also showed improved HER activity in comparison to the constituent carbide and sulfide. $\mathrm{Ni}_{2} \mathrm{P}$ has been supported on various carbon structures and other high surface area substrates to enhance the activity and/or improve stability. ${ }^{[16]}$ However, to the best of our knowledge, a carbide-supported nickel phosphide composite material has not been reported.

We report the selective deposition of hexagonal $\mathrm{Fe}_{2} \mathrm{P}$-type nickel phosphide $\left(\mathrm{Ni}_{2} \mathrm{P}\right)$ by using a hydrothermal synthesis method on hexagonal $\mathrm{Fe}_{2} \mathrm{~N}$-type $\beta-\mathrm{Mo}_{2} \mathrm{C}$ templated on MWCNT by the carbothermic reduction of $\mathrm{MoO}_{3}$. A facile hydrothermal synthesis route was selected because of the ease of access to various phases and potential of scalability. ${ }^{[13]}$ The $\mathrm{Ni}_{2} \mathrm{P}$ phase was selected based on the reported reproducible phase purity compared with other nickel phosphide phases. ${ }^{[17]}$ Additionally, it also possesses several low $2 \theta$ lattice planes that are within $3 \%$ lattice mismatch of the first four diffraction peaks in $\mathrm{Fe}_{2} \mathrm{~N}$-type $\mathrm{Mo}_{2} \mathrm{C}$. To analyze and compare the electrocatalytic activities of the composite materials with the corresponding nickel phosphide and molybdenum carbide, we have used HER in acidic and alkaline electrolytes as the model reaction. We propose that the selectivity in deposition on carbide instead of the ubiquitously available MWCNT surfaces is a result of the intermetallic interaction between the two metals under hydrothermal conditions and the analogous hexagonal crystal structures of the two constituent materials. We also attribute the enhancement in catalytic activity and stability of hydrothermally synthesized nickel phosphide to the interfacial sites resulting from the deposition of phosphide on carbide.

\section{Results and Discussion}

\section{Synthesis and physical characterization}

A modified hydrothermal route as reported by Deng et al. was used to prepare catalysts containing various ratios of $\mathrm{Ni}_{2} \mathrm{P}$ to $\mathrm{Mo}_{2} \mathrm{C}$, hereafter referred to as $\mathrm{Ni}_{2} \mathrm{P} @ \mathrm{Mo}_{2} \mathrm{C}$ (molar ratio). ${ }^{[13]}$ The stated ratios are based on post-synthesis inductively coupled plasma optical emission spectroscopy (ICP-OES) measurements. $\mathrm{Mo}_{2} \mathrm{C}$ was first prepared by slight modification of a previously reported carbothermic method. ${ }^{[11]}$ To achieve uniform distribution of carbide nanoparticles, the oxide-MWCNT mixture was ball-milled for $24 \mathrm{~h}$ at $300 \mathrm{rpm}$ prior to carbothermic reduction to obtain a more homogenous precursor powder. As excess red phosphorus is necessary to drive the reaction towards the product, all composite catalysts were annealed under an argon flow after hydrothermal incubation and purification to remove any unreacted phosphorus. Although phosphorus loss was observed at the annealing temperatures used here, TEM images of the phosphides and composites reveal copious amounts of phosphorus post annealing. As phosphorus contains several allotropes with a wide range of boiling points extending well above $500^{\circ} \mathrm{C}$, the observed phosphorus layers must be composed of allotropes with boiling points above $500{ }^{\circ} \mathrm{C}^{[18]}$ Additionally, a $5 \% \mathrm{H}_{2}$ mixture in $\mathrm{Ar}$ was also employed to investigate the effects of annealing under reducing environments on catalytic activities.

Based on Scherrer analysis, as-synthesized $\mathrm{Ni}_{2} \mathrm{P}_{0} \mathrm{Mo}_{2} \mathrm{C}$ contains $\mathrm{Ni}_{2} \mathrm{P}$ with crystallite size around $10 \mathrm{~nm}$ and $\mathrm{Mo}_{2} \mathrm{C}$ with around $20 \mathrm{~nm}$, as demonstrated by the diffraction patterns in Figure $1 \mathrm{a}$. On annealing under an argon flow at $500^{\circ} \mathrm{C}$ for $12 \mathrm{~h}, \mathrm{Ni}_{2} \mathrm{P}$ crystallites grow dramatically to about $50 \mathrm{~nm}$ whereas $\mathrm{Mo}_{2} \mathrm{C}$ crystallites remain unchanged, as demonstrated in Figure $1 \mathrm{~b}$. Thus, molybdenum carbide remains structurally unaffected during the hydrothermal incubation and annealing. Among the lattice planes corresponding to the first four low $2 \theta$ diffraction peaks for $\mathrm{Mo}_{2} \mathrm{C}$, only the 002 plane $(D=2.364 \AA)$ does not have a corresponding lattice plane in $\mathrm{Ni}_{2} \mathrm{P}$ that is within $5 \%$ of the lattice mismatch (Figure S1 in the Supporting

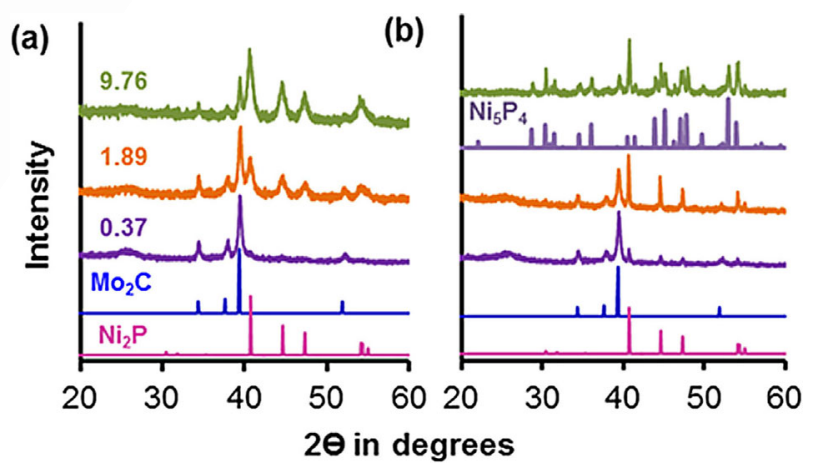

Figure 1. PXRD diffractograms of (a) the as-prepared nickel phosphide deposited on molybdenum carbide in the stated molar $\mathrm{Ni}_{2} \mathrm{P} / \mathrm{Mo}_{2} \mathrm{C}$ determined by ICP-OES measurements. (b) Phosphide-deposited carbides annealed in an argon atmosphere at $500{ }^{\circ} \mathrm{C}$ for $12 \mathrm{~h}$. The $\mathrm{Ni}_{5} \mathrm{P}_{4}$ PDF number is $(00-018-$ 0883) 
Information). More significantly, the lattice plane corresponding to the most prominent diffraction peak $(011)$ in $\mathrm{Mo}_{2} \mathrm{C}$ with a d-spacing of $2.275 \AA$ shows only a very low mismatch $(2.68 \%)$ with the most intense diffraction peak (111) in $\mathrm{Ni}_{2} \mathrm{P}$. The 010 and 012 lattice planes in $\mathrm{Mo}_{2} \mathrm{C}$ are also around $3 \%$ lattice mismatch with 020 and 030 lattice planes, respectively, in $\mathrm{Ni}_{2} \mathrm{P}$. Such a high degree of lattice alignments allows for the selective deposition of phosphide on carbide upon hydrothermal synthesis of $\mathrm{Ni}_{2} \mathrm{P}$ in the presence of $\mathrm{Mo}_{2} \mathrm{C}$.

Further analysis suggests that phosphide selectively deposits on carbide instead of unreacted MWCNT until the carbide surface saturates with phosphide. As demonstrated in Figure $1 \mathrm{a}$, all as-synthesized $\mathrm{Ni}_{2} \mathrm{P} @ \mathrm{Mo}_{2} \mathrm{C}$ catalysts contain only $\mathrm{Mo}_{2} \mathrm{C}$ and $\mathrm{Ni}_{2} \mathrm{P}$, irrespective of the phosphide-to-carbide $(\mathrm{P} / \mathrm{C})$ ratio. Upon annealing, at lower $\mathrm{P} / \mathrm{C}$ ratios, only one phase of phosphide $\left(\mathrm{Ni}_{2} \mathrm{P}\right)$ is observed, as apparent from Figure $1 \mathrm{~b}$. However, if the $\mathrm{P} / \mathrm{C}$ ratio exceeds 1.89 , a second nickel phosphide phase $\left(\mathrm{Ni}_{5} \mathrm{P}_{4}\right)$ appears. Unsupported nickel phosphide and that supported on MWCNT also contain $\mathrm{Ni}_{5} \mathrm{P}_{4}$ on annealing under an $\mathrm{Ar}$ flow. Apparently, the carbide surface is saturated with phosphide around 1.89 P/C molar ratio, and any additional phosphide is either not directly interacting with the carbide surface or is depositing on the ubiquitously available carbon surface.

The carbide-phosphide interaction is critical to maintain monophasic nickel phosphide during annealing, and emergence of a second phase indicates saturation of the carbide surface with phosphide. Thus, a P/C ratio of 1.89 is referred to as the optimum molar ratio hereafter. XRD diffractograms for all the composite catalysts investigated here do not indicate the formation of possible impurities, that is, crystalline monometallic compounds nickel carbide, molybdenum phosphide, and the bimetallic nickel molybdenum carbide. ${ }^{[5,6,19]}$ The annealing temperatures employed here are below the formation temperatures reported for carbides and hydrothermal incubation of nickel chloride in the presence of $\mathrm{Mo}_{2} \mathrm{C}$ does not indicate the presence of crystalline phosphides. ${ }^{[9]}$

High-resolution (HR)-STEM micrographs, high angle annular dark field (HAADF) images, and energy-dispersive X-ray (EDX) maps in Figure $2 \mathrm{~b}-\mathrm{e}$ support the conclusion that the phosphide nanoparticles preferentially deposit on carbide nanoparticles. The most intense regions of $\mathrm{Mo}$ and $\mathrm{Ni}$ in Figure $2 \mathrm{c}, \mathrm{d}$ correspond to the bright areas in the HAADF image in Figure $2 \mathrm{~b}$, indicating that the two transition metals are spatially co-localized. The overlap between $\mathrm{Ni}$ (Figure $2 \mathrm{~d}$ ) and $\mathrm{P}$ (Figure $2 \mathrm{e}$ ) corroborates the XRD evidence in Figure 1 for formation of nickel phosphide instead of metallic nickel nanoparticles deposited on carbide. Additionally, composite catalysts are dispersed in a network of MWCNT (inset, Figure $2 \mathrm{a}$ ). Prior to annealing, spherical phosphide particles around $10 \mathrm{~nm}$ are deposited on bigger carbide particles. The apparent composite particle size in Figure $2 \mathrm{~b}$ is around $50 \mathrm{~nm}$, which closely matches the estimation using Scherrer equation.

Catalyst surfaces were probed by using X-ray photoelectron spectroscopy (Figure 3). The high-resolution Mo $3 \mathrm{~d}$ spectrum in Figure $3 \mathrm{a}$ is analogous to the $\mathrm{Mo}_{2} \mathrm{C}$ surface described previously for carbothermic reduction derived $\mathrm{Mo}_{2} \mathrm{C}^{[11,20]}$ Porosoff et al. demonstrated that carbides have partially oxidized surfaces,

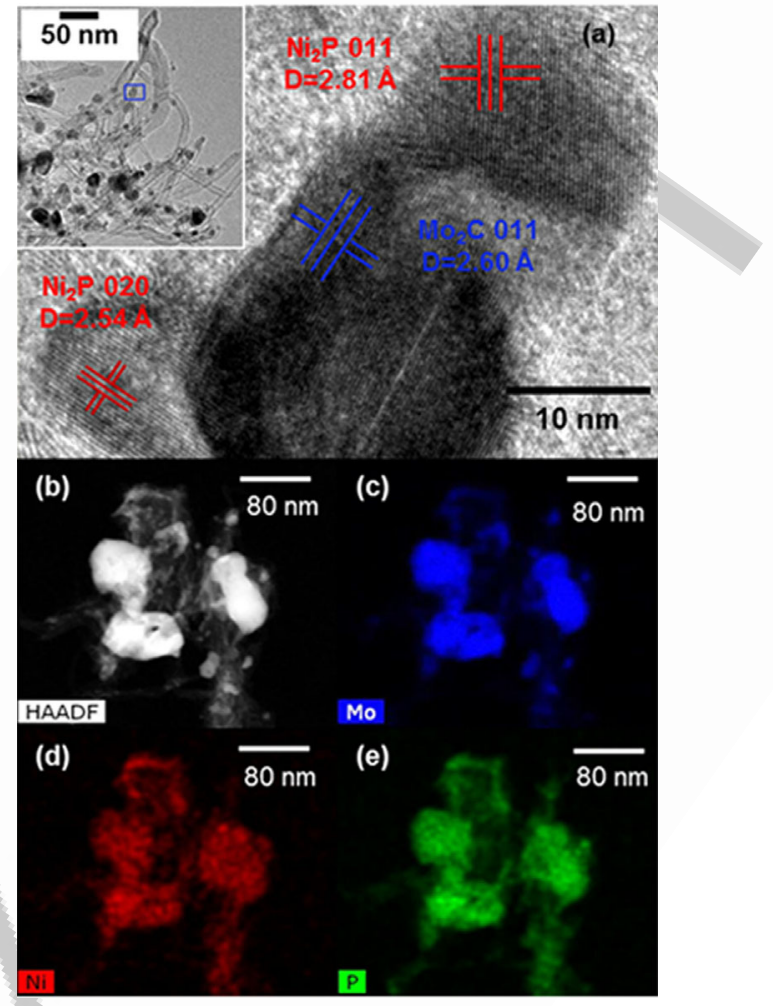

Figure 2. (a) High-resolution scanning transmission electron micrograph (HRTEM) of as synthesized $\mathrm{Ni}_{2} \mathrm{P} @ \mathrm{Mo}_{2} \mathrm{C}$. Inset is the larger area TEM image with the area corresponding to the HR-STEM image marked in the blue rectangle. (b) High-angle annular dark field (HAADF) image of the annealed $\mathrm{Ni}_{2} \mathrm{P} @ \mathrm{Mo}_{2} \mathrm{C}$ with ICP-OES measured molar $\mathrm{Ni}_{2} \mathrm{P} / \mathrm{Mo}_{2} \mathrm{C}=0.37$. Corresponding energy dis persive X-ray spectroscopy (EDX) elemental maps for (b) molybdenum, (c) nickel, and (d) phosphorus.

and the degree of oxidation fluctuates during the course of a reaction cycle. ${ }^{[21]}$ The $2 \mathrm{p}$ spectrum for $\mathrm{Ni}$ from $\mathrm{Ni}_{x} \mathrm{P}_{y}$ in Figure $3 \mathrm{~b}$ indicates the presence of phosphided and oxidized nickel in addition to the broad satellite structures at higher binding energies. ${ }^{[22]}$ Similarly, the $2 p$ spectrum corresponding to $P$ from $\mathrm{Ni}_{x} \mathrm{P}_{y}$ in Figure $3 \mathrm{C}$ reveals peaks that have previously been assigned as nickel phosphide and nickel phosphate. ${ }^{[23]}$

The Mo 3d spectrum for the composite material in Figure $3 d$ indicates an increase in the relative intensity of peaks at lower binding energies compared with $\mathrm{Mo}_{2} \mathrm{C}$ in Figure $3 \mathrm{a}$. There is also a shift of about $0.5 \mathrm{eV}$ to higher binding energies for all peaks for the composite material in comparison to $\mathrm{Mo}_{2} \mathrm{C}$ (Table S1 in the Supporting Information). The Ni2p spectra from the composite in Figure $3 e$ indicates formation of only oxidized nickel species and the $P 2 p$ spectra in Figure $3 \mathrm{f}$ reveals the formation of $\mathrm{P}_{2} \mathrm{O}_{5} \cdot{ }^{\left[{ }^{[23 a}, 24\right]}$ The relative growth of lower binding energy peaks indicates an increase in the metallic nature of the surface in the composite material with respect to $\mathrm{Mo}_{2} \mathrm{C}^{[25]}$ The increase in binding energy for the $3 \mathrm{~d}$ peaks has previously been attributed to the increased intermetallic interaction between the transition metals. ${ }^{[23 a, 26]}$ Thus, the higher binding energy shift suggests an intermetallic interaction between $\mathrm{Mo}$ from $\mathrm{Mo}_{2} \mathrm{C}$ and $\mathrm{Ni}$ from $\mathrm{Ni}_{2} \mathrm{P}$ that was hydrothermally deposited on $\mathrm{Mo}_{2} \mathrm{C}$. Formation of phosphate and oxidized nickel species on the surface has been attributed to oxidation 


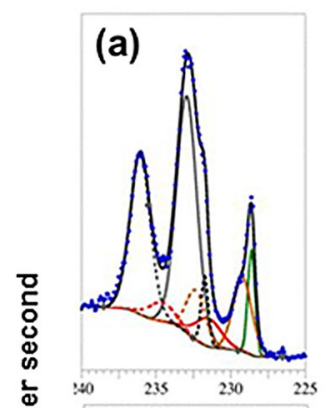

(b)
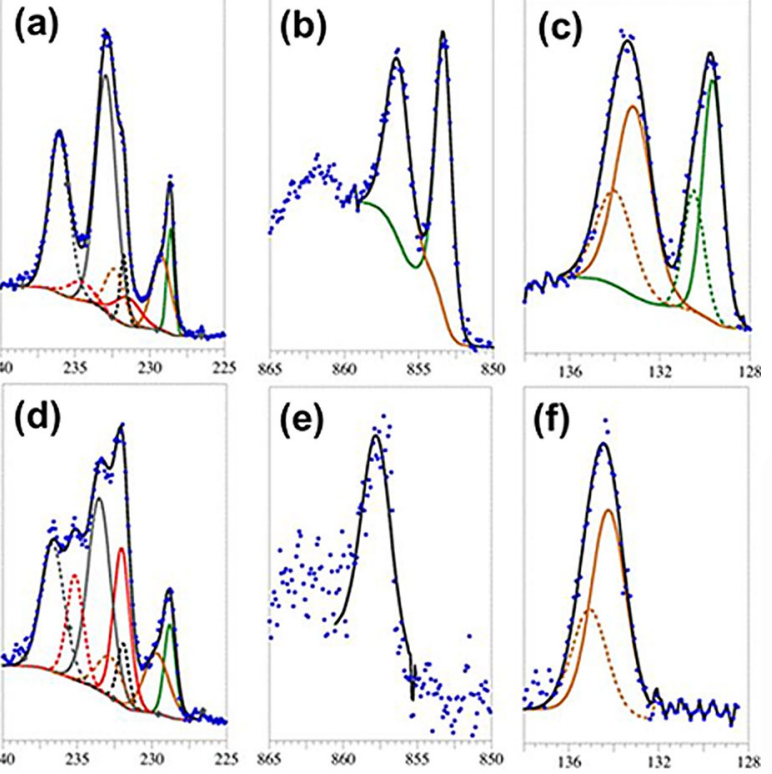

(f)

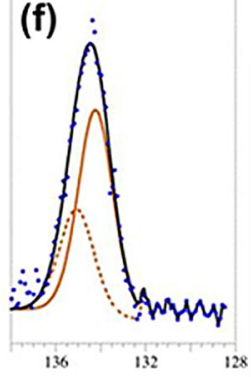

Binding energy $(\mathrm{eV})$

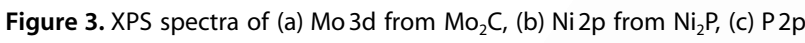

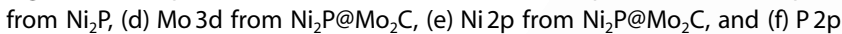
from $\mathrm{Ni}_{2} \mathrm{P}_{\mathrm{M}} \mathrm{Mo}$ C. All catalysts were annealed post-synthesis prior to XPS measurements and the data are normalized with respect to the $C 1 \mathrm{~s}$ peak set to $284.8 \mathrm{eV}$. Lines with the same color within a spectrum but solid and dotted are pairs of peak splitting for a bonding type.

upon contact with air. ${ }^{[27]}$ The shift to higher binding energy for the oxidized phosphorus peak and the absence of peaks related to phosphide in the composite material is also consistent with previous observations on deposition of nickel phosphide on various supports such as alumina, silica, and nickel foam. ${ }^{[28]}$

\section{Electrochemical characterization}

Electrocatalytic activities of the carbide, phosphide, and composite materials with various $\mathrm{P} / \mathrm{C}$ ratios were measured in $0.5 \mathrm{M}$ sulfuric acid $(\mathrm{pH} 0.30)$ and $0.1 \mathrm{M} \mathrm{KOH}(\mathrm{pH} 13)$ by using a threeelectrode rotating disc electrode. The electrolyte was saturated with a hydrogen flow prior to electrochemical measurements and was continuously purged during the measurements. All potentials are adjusted to the reversible hydrogen electrode (RHE). Current densities are calculated based on geometric surface area of the working electrode and the catalyst loading is $0.2 \mathrm{mg} \mathrm{cm}^{-2}$. The onset potential is defined as the applied potential (vs. RHE) required to generate $10 \mathrm{mAcm}^{-2}$, unless otherwise stated.

The XRD plot in Figure $4 \mathrm{a}$ indicates that the $\mathrm{Ni}_{5} \mathrm{P}_{4}$ phase has emerged at $450^{\circ} \mathrm{C}$ if hydrothermally synthesized $\mathrm{Ni}_{2} \mathrm{P}$ (red) or $\mathrm{Ni}_{2} \mathrm{P}$ supported on MWCNT (black) was annealed under argon. We chose $450^{\circ} \mathrm{C}$ instead of $500^{\circ} \mathrm{C}$ so that we could compare these results with previous reports on nickel phosphide electrocatalysts. ${ }^{[12]}$ Annealing $\mathrm{Ni}_{2} \mathrm{P}$ in a reducing environment $(5 \%$ $\mathrm{H}_{2}$ ) increases the proportion of $\mathrm{Ni}_{5} \mathrm{P}_{4}$ (blue) in the nickel phosphide matrix. $\mathrm{Ni}_{5} \mathrm{P}_{4}$ has previously been reported to be a highly active electrocatalyst for HER in acid if synthesized uti-
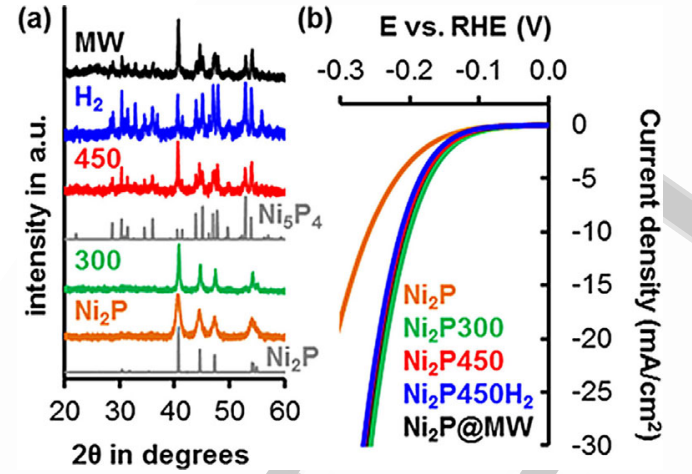

Figure 4. PXRD diffractograms (a) and corresponding HER polarization curves for $\mathrm{Ni}_{2} \mathrm{P}$ annealed at various temperatures and under varying conditions (b). Numbers and $\mathrm{H}_{2}$ after $\mathrm{Ni}_{2} \mathrm{P}$ in (b) represent annealing temperatures in ${ }^{\circ} \mathrm{C}$ and annealing in $5 \%$ hydrogen in argon, respectively.

lizing a solvothermal synthesis method. ${ }^{[29]}$ Encapsulation in or supporting $\mathrm{Ni}_{2} \mathrm{P}$ on high surface area carbon has also been shown to significantly improve the HER activities. ${ }^{[30]}$ However, Figure $4 \mathrm{~b}$ indicates that the HER activities of hydrothermally derived $\mathrm{Ni}_{2} \mathrm{P}$ remain unchanged irrespective of annealing conditions, support, or presence of $\mathrm{Ni}_{5} \mathrm{P}_{4}$. The initial improvement in HER activity upon annealing at $300^{\circ} \mathrm{C}$ can be attributed to the removal of organic adsorbates on the catalyst surface as described previously for nickel phosphide synthesized by using trioctylphosphine. ${ }^{[12]}$ Unreacted phosphorus was volatilized at $450^{\circ} \mathrm{C}$ during annealing in the tube furnace with simultaneous appearance of $\mathrm{Ni}_{5} \mathrm{P}_{4}$ if XRD patterns of the resulting powder were collected post-annealing.

However, supporting $\mathrm{Ni}_{2} \mathrm{P}$ on $\mathrm{Mo}_{2} \mathrm{C}$ improves the HER activities significantly in both acidic and basic electrolytes. As listed in Table 1, the HER overpotential generally decreases as the molar ratio of phosphide increases, under acidic electrolyte conditions. If the electrolyte is switched to $0.1 \mathrm{M} \mathrm{KOH}$, the onset potential becomes more positive up to the optimum

Table 1. Electrochemical parameters in acid $(\mathrm{A}, \mathrm{pH} 0.30)$ and base $(\mathrm{B}$, $\mathrm{pH}$ 13) for catalysts annealed at $500^{\circ} \mathrm{C}$ for $12 \mathrm{~h}$ under $\mathrm{Ar}$ flow at $0.5 \mathrm{Lmin}^{-1}$

\begin{tabular}{|c|c|c|c|c|c|c|c|c|}
\hline \multirow[t]{2}{*}{$\mathrm{Cat}^{[\mathrm{a]}]}$} & \multicolumn{2}{|c|}{$\begin{array}{l}\text { ECSA } \\
{\left[\mathrm{cm}^{2}\right]}\end{array}$} & \multicolumn{2}{|c|}{$\eta_{10}$ vs. RHE $[\mathrm{mV}]$} & \multicolumn{2}{|c|}{$\begin{array}{l}\text { Tafel Slope } \\
{\left[\mathrm{mVDec}^{-1}\right]}\end{array}$} & \multicolumn{2}{|c|}{$\begin{array}{l}\text { Ex. Current } \\
{\left[\mu \mathrm{Acm}^{-2}\right]}\end{array}$} \\
\hline & $A$ & B & $A$ & B & $A$ & B & $A$ & B \\
\hline $\mathrm{Mo}_{2} \mathrm{C}$ & 37 & 27 & 192 & 225 & 60 & 56 & 6 & 2 \\
\hline 0.16 & 42 & 18 & 231 & 272 & 69 & 58 & 4 & 1 \\
\hline 0.37 & 41 & 21 & 239 & 265 & 82 & 66 & 13 & 2 \\
\hline 0.76 & 32 & 19 & 212 & 238 & 75 & 60 & 16 & 1 \\
\hline 1.89 & 35 & 13 & 196 & 237 & 67 & 62 & 18 & 2 \\
\hline 4.69 & 22 & 13 & 196 & 246 & 72 & 72 & 12 & 6 \\
\hline 9.76 & 14 & 9 & 190 & 269 & 88 & 71 & 69 & 3 \\
\hline 18.8 & 8 & 4 & 184 & 321 & 90 & 84 & 57 & 2 \\
\hline $\mathrm{Ni}_{x} \mathrm{P}_{y}$ & 3 & 6 & 217 & 327 & 110 & 118 & 44 & 18 \\
\hline $\mathrm{MW}^{[\mathrm{b}]}$ & 10 & 9 & 219 & 464 & 88 & 119 & 54 & 7 \\
\hline $\mathrm{mix}^{[\mathrm{c}]}$ & 19 & 16 & 185 & 239 & 74 & 67 & 30 & 3 \\
\hline
\end{tabular}

[a] Numbers represent $\mathrm{Ni} / \mathrm{Mo}$ ratio. [b] $\mathrm{Ni}_{x} \mathrm{P}_{y}$ deposited on multiwalled carbon nanotubes. [c] Physical mixture of phosphide and carbide in the same ratio as 1.89 catalysts. 
$\mathrm{Ni}_{2} \mathrm{P}$ loading of 1.89. At the highest $\mathrm{Ni}_{2} \mathrm{P}$ loading (18.8), the HER activity is analogous to $\mathrm{Ni}_{x} \mathrm{P}_{y}$. The increase in Tafel slope and decrease in electrochemical surface area (ECSA; Figure S2 in the Supporting Information) at higher ratios can be attributed to the increased coverage of $\mathrm{Mo}_{2} \mathrm{C}$ with $\mathrm{Ni}_{2} \mathrm{P}$ to form interfacial sites and deposition of phosphide on high surface area MWCNT, respectively. Higher loadings of phosphide $(>1.89)$ result in mixed phases of nickel phosphide upon annealing, and the HER activity continues to improve in acid electrolyte. However, the activity starts to decrease beyond the optimum carbide phosphide ratio in base.

Despite a significant reduction in ECSA for $\mathrm{Ni}_{2} \mathrm{P} @ \mathrm{Mo}_{2} \mathrm{C}(9.76)$ and $\mathrm{Ni}_{2} \mathrm{P} @ \mathrm{Mo}_{2} \mathrm{C}(18.8)$, the increased HER activity in acid indicates either a higher density of active sites or higher turnover frequency (TOF) of the interfacial active sites. ${ }^{[1]}$ An increased Tafel slope to $120 \mathrm{mV} /$ decade also indicates that the HER reaction rate is mostly determined by the reduction of hydroniums ion on the catalyst surface through the Volmer step. ${ }^{[32]}$ The increase in overpotential of the composite catalyst at low phosphide ratios in comparison to $\mathrm{Mo}_{2} \mathrm{C}$ can be attributed to the deposition of phosphorus on carbide active sites that cannot form phosphide-carbide interfaces. The $\mathrm{P} 2 \mathrm{p}$ peak in the X-ray photoelectron spectroscopy (XPS) in Figure $3 \mathrm{~F}$ indicates formation of phosphate on the surface. Thus, the analyte may be blocked from interacting with the active site by the surface phosphate species. At higher phosphide loading all the active sites on carbide must be converting to the interfacial sites and thus the overpotential is lower.

In the absence of an accurate insight into the nature and population of active sites on the surfaces, estimation of the catalytic properties such as turnover frequencies (TOF) of these materials cannot be quantified with precision. Instead, the Tafel slope and the associated exchange current densities can be used to infer the intrinsic catalytic properties of the materials. ${ }^{[31]}$ The higher exchange current in general for the catalysts in acidic media in comparison to alkaline media in Table 1, indicates enhanced comparative electrochemical interaction between the catalyst and the electrolyte at lower $\mathrm{pH}$. The exchange current densities generally also increase in acid electrolyte with the increase in phosphide loading. The observations indicate that nanocrystalline phosphides may be better electrical conductors than the corresponding carbides and MWCNT.

Previous studies employed annealing in reducing environments to primarily remove the ligands adsorbed on the surface during the solvothermal decomposition method. ${ }^{[12]}$ On annealing of $\mathrm{Mo}_{2} \mathrm{C}$ and the composite catalyst with optimized phosphide loading (1.89) under argon and in the presence of $5 \%$ $\mathrm{H}_{2}$, the electrocatalytic activity of $\mathrm{Mo}_{2} \mathrm{C}$ is analogous to that of nickel phosphide (Figure $4 \mathrm{a}$ ). The activity of annealed $\mathrm{Mo}_{2} \mathrm{C}$ improves in comparison to that of as-synthesized carbide, but remains unchanged irrespective of annealing under an inert or reducing environment (Figure S3a in the Supporting Information). Annealing the composite catalyst under a reducing environment leads to a lower HER overpotential in comparison to annealing under an inert atmosphere, as apparent from Figure S3 b in the Supporting Information. Apparently, the passi- vated carbide-phosphide interface leads to an improvement in electrocatalytic activity.

However, all the $\mathrm{Ni}_{2} \mathrm{P} @ \mathrm{Mo}_{2} \mathrm{C}$ catalysts annealed under $\mathrm{H}_{2}$ contain two hexagonal phases (Figure $\mathrm{S} 4$ ) irrespective of phosphide to carbide ratio unlike in Figure $1 \mathrm{~b}$, where the $\mathrm{Ni}_{5} \mathrm{P}_{4}$ phase was observed only at higher ratios than 1.89 on annealing under inert argon atmosphere. The apparent improvement in overpotential could be a result of the emergence of the second phosphide phase, $\mathrm{Ni}_{5} \mathrm{P}_{4}$.

A comparison of HER activities of single-phase phosphidedeposited catalysts, that is, $\mathrm{Ni}_{2} \mathrm{P}_{0} \mathrm{Mo}_{2} \mathrm{C}$ and $\mathrm{Ni}_{5} \mathrm{P}_{4} @ \mathrm{Mo}_{2} \mathrm{C}$, was not possible because hydrothermal synthesis could not be used to access the single-phase $\mathrm{Ni}_{5} \mathrm{P}_{4}$ nanomaterial on its own or deposited on $\mathrm{Mo}_{2} \mathrm{C}$. Previously, Laursen et al. reported that a solvothermal method can be utilized to synthesize phasepure micron-sized $\mathrm{Ni}_{5} \mathrm{P}_{4}$ spheres, and the catalyst showed enhanced HER activities. ${ }^{[29]}$ The same investigation also reported that $\mathrm{Ni}_{5} \mathrm{P}_{4}$ converts to $\mathrm{Ni}_{2} \mathrm{P}$ on annealing at temperatures above $350^{\circ} \mathrm{C}$. Based on the present evidence, the two phases seem to exist in dynamic equilibrium around $350^{\circ} \mathrm{C}$. Future endeavors may be worthwhile to identify a solvothermal method to obtain $\mathrm{Ni}_{5} \mathrm{P}_{4} @ \mathrm{Mo}_{2} \mathrm{C}$ and other composites of nickel phosphide on $\mathrm{Mo}_{2} \mathrm{C}$ and so that their activities can be compared. In light of the evidence from Figure 4 and Figure S3 (in the Supporting Information), the observed enhancements in activities of the hydrothermally synthesized carbide-phosphide composite catalysts under investigation here are primary attributed to the interfacial interaction between the two transition metal compounds.

The lowest overpotential $(176 \mathrm{mV})$ to achieve $10 \mathrm{mAcm}^{-2}$ activity is afforded by annealing $\mathrm{Ni}_{2} \mathrm{P}_{0} \mathrm{Mo}_{2} \mathrm{C}(1.89)$ in a reducing environment $\left(5 \% \mathrm{H}_{2}\right)$. The overpotential to reach $40 \mathrm{mAcm}^{-2}$ HER activity can be improved by $100 \mathrm{mV}$ if hydrothermally synthesized nickel phosphide is deposited on $\mathrm{Mo}_{2} \mathrm{C}$ (Figure $5 \mathrm{a}$ ). In addition, there is an improvement in the electrocatalytic stability of nickel phosphide if deposited on carbide, as depicted in Figure $5 \mathrm{~b}$. We employed $\mathrm{Ni}_{2} \mathrm{P} @ \mathrm{Mo}_{2} \mathrm{C}(0.76)$ for stability tests so that an identical initial applied potential could be used for both $\mathrm{Ni}_{x} \mathrm{P}_{y}$ and $\mathrm{Ni}_{x} \mathrm{P}_{y} @ \mathrm{Mo}_{2} \mathrm{C}$. The HER overpotential increased by $130 \mathrm{mV}$ for $\mathrm{Ni}_{x} \mathrm{P}_{y}$ within $18 \mathrm{~h}$ of constant potential electrolysis (CPE).

However, the corresponding increase in overpotential for $\mathrm{Ni}_{2} \mathrm{P}_{0} @ \mathrm{Mo}_{2} \mathrm{C}(0.76)$ is only $20 \mathrm{mV}$ (Table S2 in the Supporting Information). The overpotential increases by $15 \mathrm{mV}$ for $\mathrm{Mo}_{2} \mathrm{C}$ within $18 \mathrm{~h}$ of CPE testing. The same composite catalyst showed remarkable electrochemical stability for $240 \mathrm{~h}$ if constant potential electrolysis (CPE) was conducted at $240 \mathrm{mV}$ overpotential to generate $10 \mathrm{mAcm}^{-2}$ (Figure S5a in the Supporting Information). Comparison of the initial linear sweep voltammetry (LSV) curve with the one collected after $240 \mathrm{~h}$ showed an increase of $9 \mathrm{mV}$ in overpotential (Figure S5b in the Supporting Information).

For comparison, a physical mixture of $\mathrm{Ni}_{x} \mathrm{P}_{y}$ and $\mathrm{Mo}_{2} \mathrm{C}$ was prepared by grinding annealed phosphide and carbide in the same molar ratio as optimized ratio (1.89). Although the significance of the $\mathrm{Ni}-\mathrm{Mo}$ bimetallic catalyst is highlighted by the lower overpotential than $\mathrm{Mo}_{2} \mathrm{C}$ and $\mathrm{Ni}_{x} \mathrm{P}_{y}$ for the physical mix- 


\section{Potential vs. RHE (V)}
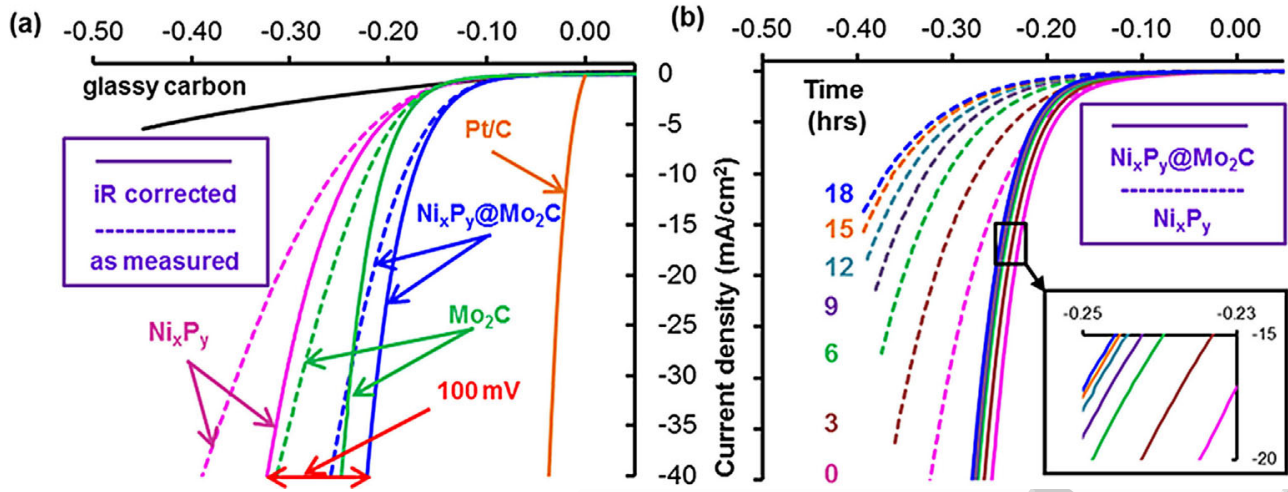

Figure 5. (a) iR corrected (solids) and as-obtained (dashed) HER polarization curves in $0.5 \mathrm{M} \mathrm{H}_{2} \mathrm{SO}_{4}$ for catalysts annealed at $450{ }^{\circ} \mathrm{C}$ for $12 \mathrm{~h}$ under $5 \% \mathrm{H}_{2}$ blended with Ar. The ICP-OES measured molar $\mathrm{Ni}_{2} \mathrm{P}_{2} \mathrm{Mo}_{2} \mathrm{C}$ ratio was 1.89 before annealing in $\mathrm{H}_{2}$ environment. (b) Polarization curves for nickel phosphide (dashed) and nickel phosphide-deposited $\mathrm{Mo}_{2} \mathrm{C}$ (solids) after constant potential electrolysis (CPE) to generate $10 \mathrm{~mA} \mathrm{~cm}{ }^{-2}$ for the stated hours. The $\mathrm{Ni}_{2} \mathrm{P} / \mathrm{Mo}_{2} \mathrm{C}$ was 0.76 pre-annealing in $\mathrm{H}_{2}$. The glassy carbon working electrode was rotated at $3500 \mathrm{rpm}, \mathrm{Hg} / \mathrm{HgSO}_{4}$ was the reference electrode and a gold wire as the counter electrode.

ture (mix) catalyst in Table 1, the extended stability can only be achieved if nickel phosphide is deposited and immobilized on carbide by hydrothermal incubation and high-temperature annealing. Rapid deactivation of hydrothermally synthesized unsupported $\mathrm{Ni}_{2} \mathrm{P}$ in Figure $5 \mathrm{~b}$ indicates that interaction with the support is crucial for the stability whereas bimetallic properties are critical for activity enhancement.

\section{Conclusions}

We have demonstrated that nickel phosphide can be selectively deposited on molybdenum carbide by using a hydrothermal synthesis method. Emergence of a second phosphide phase, $\mathrm{Ni}_{5} \mathrm{P}_{4}$, upon annealing at $500^{\circ} \mathrm{C}$, indicates saturation of the carbide surface with phosphide. Unsupported phosphide and phosphide supported on carbon also shows a biphasic composition. The HER activity and stability of the carbide deposited with phosphide are superior to unsupported nickel phosphide. The enhancement in activity and stability is a result of the interfacial phosphide-carbide interaction. Our investigations demonstrate the utility of advanced carbide-phosphide composite materials for electrochemical energy conversion technologies.

\section{Experimental Section}

\section{Safety statement}

Synthesis routes for nickel phosphide and phosphide-deposited carbides utilized here require handling elemental red phosphorus under high temperature and pressure. Under such conditions, toxic and explosive phosphorus compounds can be released that are known to cause health and safety hazards. All personnel involved in such synthesis are advised to read safety documents obtained during the purchase of the chemicals and equipment. Hydrothermal reactors should be allowed to equilibrate to room temperature before opening inside a well-ventilated fume hood. Furnaces should also be allowed to equilibrate with the fume hood temper- ature before unloading the annealing boats containing phosphides.

\section{Materials}

$\mathrm{MoO}_{3}, \mathrm{MWCNT}(70-80 \% \mathrm{C}), \mathrm{P}$ (red), and $\mathrm{NiCl}_{2} \cdot 6 \mathrm{H}_{2} \mathrm{O}$ were purchased from Sigma-Aldrich. Ethanol, methanol, $\mathrm{HNO}_{3}$, and $\mathrm{HCl}$ were purchased from Fisher Scientific. HF and $\mathrm{H}_{3} \mathrm{BO}_{3}$ were purchased from Acros Organics. Stock solutions for ICP-OES of $\mathrm{Ni}$ $(20 \mathrm{ppm}), \mathrm{Mo}(1000 \mathrm{ppm})$, and $\mathrm{P}(1000 \mathrm{ppm})$ were purchased from SPEX CertiPrep. Nafion solution (5 wt \%, lonPower) and methanol (99.9\% Sigma-Aldrich) were used for ink preparation for electrochemical half-cell experiments conducted in $\mathrm{H}_{2} \mathrm{SO}_{4}$ (99.9999\% Alfa Aesar) and $\mathrm{KOH}$ (99.99\% Sigma-Aldrich) diluted to $0.5 \mathrm{M}$ and $0.1 \mathrm{M}$, respectively, with $18.2 \mathrm{MOhm} \mathrm{cm}$ water (Milli-Q). Ultrahigh purity nitrogen, hydrogen, and argon were obtained from Airgas. All the materials were used as purchased unless otherwise stated.

\section{Catalyst synthesis}

$\mathrm{Mo}_{2} \mathrm{C}$ synthesis was modified from the carbothermic reduction method reported recently. ${ }^{[11]}$ A 20:1 ball to precursor mixture of MWCNT and $\mathrm{MoO}_{3}$ was ball-milled at $300 \mathrm{rpm}$ for $20 \mathrm{~h}$ to prepare a homogenous mixture. The mixture was placed on a quartz boat annealed in a tube furnace equipped with temperature control. The furnace ramped to $950^{\circ} \mathrm{C}$ at $1{ }^{\circ} \mathrm{Cmin}^{-1}$ under argon flow at $0.5 \mathrm{~L} \mathrm{~min}^{-1}$. The furnace was allowed to cool down to room temperature naturally before collecting the powder and grinding, using an agate mortar and pestle. $\mathrm{Ni}_{2} \mathrm{P}$ synthesis was performed as described by Deng et al. ${ }^{[13]}$ Various $\mathrm{Ni}_{2} \mathrm{P} @ \mathrm{Mo}_{2} \mathrm{C}$ catalysts were prepared as per the synthesis route for $\mathrm{Ni}_{2} \mathrm{P}$ but with the addition of $\mathrm{Mo}_{2} \mathrm{C}$ into the precursor mixture. Briefly, to obtain the $1.89 \mathrm{Ni}_{2} \mathrm{P}$ to $\mathrm{Mo}_{2} \mathrm{C}$ ratio, $\mathrm{NiCl}_{2} \cdot 6 \mathrm{H}_{2} \mathrm{O}(0.95 \mathrm{~g})$ was added to deionized (DI) water $(30 \mathrm{~mL})$ and the solution stirred at $400 \mathrm{rpm}$ for $10 \mathrm{~min}$. Red $\mathrm{P}$ $(0.70 \mathrm{~g})$ was stirred in followed by $\mathrm{Mo}_{2} \mathrm{C}(0.41 \mathrm{~g})$, and the mixture stirred for an additional $20 \mathrm{~min}$. Then, the slurry was transferred into a Teflon-lined hydrothermal bomb from Parr Instruments and heated to $140^{\circ} \mathrm{C}$ for $12 \mathrm{~h}$. After cooling to room temperature, the black suspension was washed by centrifugation at $4000 \mathrm{rpm}$ with three $50 \mathrm{~mL}$ portions of $\mathrm{DI}$ water and one portion of anhydrous 
ethanol. The supernatant was discarded and the residue was dried at $60^{\circ} \mathrm{C}$ under vacuum for $6 \mathrm{~h}$. The resulting powder was ground with a mortar and pestle and annealed in a tube furnace under argon or $5 \% \mathrm{H}_{2}$ in argon flow at $500^{\circ} \mathrm{C}$ for $12 \mathrm{~h}$ to remove excess P. $\mathrm{Ni}_{2} \mathrm{P} @ M W C N T$ was also prepared by replacing $\mathrm{Mo}_{2} \mathrm{C}$ with MWCNT and a physical mixture of $\mathrm{Ni}_{2} \mathrm{P}$ and $\mathrm{Mo}_{2} \mathrm{C}$ was obtained by grinding $\mathrm{Mo}_{2} \mathrm{C}(0.41 \mathrm{~g})$ and of $\mathrm{Ni}_{2} \mathrm{P}(0.30 \mathrm{~g})$ for $20 \mathrm{~min}$.

\section{Physical characterization}

Powder X-ray diffraction (PXRD) patterns were collected with a Pananalytical Empyrean diffractometer with CuK alpha1 source $(\lambda=$ $1.5406 \AA$ ) with the voltage and current were $45 \mathrm{kV}$ and $40 \mathrm{~mA}$, respectively. Instrumental broadening for Scherrer analysis was determined by using a $\mathrm{LaB}_{6}$ standard (660) from the National Institute of Standards and Technology (NIST). Scanning electron micrographs were collected with a Zeiss Dual Beam FIB/SEM instrument. TEM images were collected with a Zeiss Libra 200 HT FE MC instrument. XRD, TEM, and SEM were collected at the Joint Institute for Advanced Materials (JIAM) at the University of Tennessee, Knoxville. The transmission electron microscopy (TEM) associated with energy dispersive X-ray spectroscopy (EDX) analysis were performed with a FEl Tecnai Osiris $200 \mathrm{kV}$ (S)TEM instrument equipped with EDX. All EDX analysis was conducted at the Vanderbilt Institute of Nanoscale Science and Engineering (VINSE). The TEM samples were prepared by sonicating the catalyst $(1 \mathrm{mg})$ in methanol $(5 \mathrm{~mL}$ ) for $20 \mathrm{~min}$ and drop-casting $5 \mu \mathrm{L}$ of the suspension on copper grids with formvar film on 400 square mesh.

XPS analyses were performed by using an Ulvac-PHI Versaprobe 5000. Monochromatic $\mathrm{AlK}_{\alpha}$ X-rays $(1486 \mathrm{eV})$, a $100 \mu \mathrm{m}$ diameter $\mathrm{X}$ ray spot, and a takeoff angle of $60^{\circ}$ off sample normal were used in each acquisition. Pass energies of $187.7 \mathrm{eV}$ and $23.5 \mathrm{eV}$ were used for the survey and high-resolution acquisitions, respectively. Charge neutralization was accomplished by using $1.1 \mathrm{eV}$ electrons and $10 \mathrm{eV} \mathrm{Ar}{ }^{+}$ions. The powder samples were pressed into a piece of indium foil and the foil was screwed onto a sample puck. Placing the $-\mathrm{CH}_{2}$ - type bonding in the carbon $1 \mathrm{~s}$ spectrum at $284.8 \mathrm{eV}$ corrected any minor energy shifts resulting from charging. Relative atomic concentrations were calculated by using peak areas and PHI handbook sensitivity factors. ${ }^{[33]}$

lon-coupled plasma optical emission spectroscopy (ICP-OES) measurements were performed with an Optima 7300 DV spectrometer from PerkinElmer. Catalysts were digested by using a microwaveassisted method prior to ICP-OES analysis analogous to one described previously. ${ }^{[34]}$ Briefly, the catalyst $(1.0-2.0 \mathrm{mg})$ was suspended in a solution consisting of concentrated solutions of $\mathrm{HCl}(3 \mathrm{~mL})$, $\mathrm{HNO}_{3}(1 \mathrm{~mL})$, and $\mathrm{HF}(0.2 \mathrm{~mL})$. The mixture was incubated for $20 \mathrm{~min}$ at $1150 \mathrm{~W}$ by using a Multiwave 3000 microwave from Anton Parr. After digestion and cooling, $\mathrm{H}_{3} \mathrm{BO}_{3}(1 \mathrm{~mL})$ was added and the concentration was brought to ICP-OES measurement range by diluting with $1 \mathrm{M} \mathrm{HNO}_{3}$ before analysis.

\section{Electrochemical characterization}

A Pine Instruments rotating disk electrode (RDE) rotator, glassy carbon electrodes $\left(0.1963 \mathrm{~cm}^{2}\right)$, electrochemical cells, and a biologic VMP-3 potentiostat were used for all electrochemical measurements. A Radiometer Analytical XR-200 $\mathrm{Hg} / \mathrm{HgSO}{ }_{4}$ (acid) or XR-400 $\mathrm{Hg} / \mathrm{HgO}$ (base) reference electrode, and gold wire counter electrode were used. The reference electrode potentials versus RHE were determined by measuring the open circuit voltage (OCV) of a Pt electrode in hydrogen-saturated electrolyte. All procedures and data described are reported against RHE. Catalyst inks were prepared by combining catalyst material $(2.6 \mathrm{mg})$ with methanol $(0.5 \mathrm{~mL})$ and then adding $38 \mu \mathrm{L}$ of $\boldsymbol{\square}$ word missing? Nafion? for a 60:40 ratio of catalyst to Nafion. The inks were sonicated for at least $20 \mathrm{~min}$. The required volume to achieve a catalyst loading of $200 \mu \mathrm{g} \mathrm{cm}^{-2}$ was determined by depositing aliquots of the inks onto aluminum foil and weighing with a Mettler Toledo XP2U balance. The volume typically ranged between $8-12 \mu \mathrm{L}$. Glassy carbon (GC) electrodes were prepared by polishing with 5.0 micron then 0.05 micron alumina powders, rinsing, and sonicating in ultrapure water for $5 \mathrm{~min}$ and finally sonicated in $0.5 \mathrm{M} \mathrm{H}_{2} \mathrm{SO}_{4}$ for $5 \mathrm{~min}$. The electrodes were cleaned electrochemically by scanning $10 \mathrm{CV}$ cycles at $50 \mathrm{mV} \mathrm{s}^{-1}$ between 0.1 and $-0.8 \mathrm{~V}$ in nitrogen-saturated electrolyte. The background activity of the clean GCE electrodes was then measured by collecting $3 \mathrm{CV}$ s between 0.1 and $-0.8 \mathrm{~V}$ at a scan rate of $5 \mathrm{mVs}^{-1}$ in hydrogen-saturated electrolyte. Measurements were made while rotating the electrode at $3500 \mathrm{rpm}$ to remove hydrogen bubbles. Afterward, the predetermined volume of catalyst ink was deposited onto the electrode. The catalyst testing was conducted in hydrogen-saturated electrolyte. The catalyst surface was first electrochemically cleaned in a similar manner to the bare GC electrode with the potential window selected to limit the current to $50 \mathrm{~mA} \mathrm{~cm}^{-2}$ in acid and $20 \mathrm{mAcm}^{-2}$ in base. These ranges were selected because electrode delamination occurred at higher current densities. After cleaning, the hydrogen evolution activity was measured by collecting $5 \mathrm{CV}$ s within the same potential window at a $5 \mathrm{mV} \mathrm{s}^{-1}$ scan rate. Potentioelectrochemical impedance spectroscopy measurements were conducted at $0 \mathrm{~V}$ for each electrode to iR correct the data. The electrochemical surface area (ECSA) of the catalysts was determined by measurement of the double-layer capacitance $\left(C_{\mathrm{DL}}\right)$. These measurements were made by collecting CVs within the range $0-0.3 \mathrm{~V}$ (acid) and $0-0.4 \mathrm{~V}$ (base) at $100,50,20,10$, and $5 \mathrm{mV} \mathrm{s}^{-1}$ scan rates. The fifth cycle was collected for the first three scan rates and the third cycle for the latter two to ensure stable values were selected. For most catalysts, no faradaic processes were observed within these regions. Within the regions where no faradaic processes are occurring, the current results from double layer capacitance according to the Equations (S1) and (S2) in the Supporting Information, where $v$ represents the scan rate and $i_{\mathrm{a}}$ and $i_{\mathrm{c}}$ are the cathodic and anodic currents, respectively. The double layer capacitance was determined by plotting the difference between $i_{\mathrm{a}}$ and $i_{\mathrm{c}}$ in the middle of the potential region versus the scan rate, where the slope is equal to twice the double layer capacitance. The ECSA is related to $C_{\mathrm{DL}}$ according to Equation (S4), where $C_{\mathrm{s}}$ is the area-specific capacitance of an atomically smooth electrode of the same material under the same conditions (e.g., temperature, electrolyte, concentration, etc.). As $C_{\mathrm{s}}$ is not available for these catalysts, we have chosen values of $30 \mu \mathrm{Fc}^{-2}$ for $0.5 \mathrm{M} \mathrm{H}_{2} \mathrm{SO}_{4}$ and $40 \mu \mathrm{Fc}^{-2}$ for $\mathrm{KOH}$ based on literature values of $\mathrm{Ni}$ and Mo electrodes. ${ }^{[35]}$ An example of the ECSA analysis is shown in Figure $\mathrm{S} 6$ in the Supporting Information $\mathbf{\square}$ ok? $\mathbf{\square}$ for $\mathrm{Mo}_{2} \mathrm{C}$ in acid. The Tafel slopes of each polarization curve were determined around the onset potentials according to the method described previously. ${ }^{[11]}$ The stability experiments were conducted for the catalysts by holding the electrode at $-212 \mathrm{mV}$, the potential corresponding with a $10 \mathrm{mAcm}^{-2}$ current density for the $\mathrm{Ni}_{2} \mathrm{P}_{0} \mathrm{Mo}_{2} \mathrm{C}(0.76)$ and $\mathrm{Ni}_{2} \mathrm{P}$. After 3 or $8 \mathrm{~h}$, a series of five polarization curves were collected at a $5 \mathrm{mV} \mathrm{s}^{-1}$ scan rate. This process was repeated after each additional 3 or $8 \mathrm{~h}$ for a total hold CPE time. 


\section{Acknowledgments}

This project was supported by Southeastern Sun Grant Center and the US Department of Transportation, Research and Innovative Technology Administration DTO559-07-G-00050. N.L and S.C.C. also acknowledge the Southeastern Partnership for Integrated Biomass Supply Systems (IBSS), which is supported by AFRI 2011-68005-30410 from USDA NIFA. XRD was performed at the Joint Institute for Advanced Materials (JIAM) by using instruments that were procured through the DOE Nuclear Energy University Program (DE-NE0000693) 12-3528. STEM was performed at the Vanderbilt Institute for Nanoscience and Engineering (VINSE) by using an instrument procured using funds provided by the NSF (NSF EPS 1004083 TN-SCORE). The authors would also like to thank Ms. Choo Hamilton (CRC), Dr. John R. Dunlap, and Dr. Maulik Patel (JIAM) for assistance with ICP, SEM, TEM, and $X R D$.

Keywords: electrocatalysis - hydrogen evolution reaction molybdenum carbide $\cdot$ nickel phosphide $\cdot$ water splitting

[1] S. W. Boettcher, T. E. Mallouk, F. E. Osterloh, J. Mater. Chem. A 2016, 4 $2764-2765$.

[2] M. Zeng, Y. Li, J. Mater. Chem. A 2015, 3, 14942-14962.

[3] C. C. McCrory, S. Jung, I. M. Ferrer, S. M. Chatman, J. C. Peters, T. F. Jaramillo, J. Am. Chem. Soc. 2015, 137, 4347-4357.

[4] X. Zou, Y. Zhang, Chem. Soc. Rev. 2015, 44, 5148-5180.

[5] X. Fan, Z. Peng, R. Ye, H. Zhou, X. Guo, ACS Nano 2015, 9, 7407-7418.

[6] a) Y. N. Regmi, B. M. Leonard, Chem. Mater. 2014, 26, 2609-2616 b) A. M. Stux, C. Laberty-Robert, K. E. Swider-Lyons, J. Solid State Chem. 2008, 181, $2741-2747$.

[7] L. Z. Zeng, S. F. Zhao, W. S. Li, Appl. Biochem. Biotechnol. 2015, 175, 2637-2646.

[8] a) X. Xu, F. Nosheen, X. Wang, Chem. Mater. 2016, 28, 6313-6320 page numbers ok? ם; b) K. Xiong, L. Li, L. Zhang, W. Ding, L. Peng, Y. Wang, S. Chen, S. Tan, Z. Wei, J. Mater. Chem. A 2015, 3, 1863-1867 c) S. Wang, J. Wang, M. Zhu, X. Bao, B. Xiao, D. Su, H. Li, Y. Wang, J. Am. Chem. Soc. 2015, 137, 15753-15759.

[9] Y. N. Regmi, G. R. Waetzig, K. D. Duffee, S. M. Schmuecker, J. M. Thode, B. M. Leonard, J. Mater. Chem. A 2015, 3, 10085-10091.

[10] C. Wan, Y. N. Regmi, B. M. Leonard, Angew. Chem. Int. Ed. 2014, 53, 6407-6410; Angew. Chem. 2014, 126, 6525-6528.

[11] Y. N. Regmi, C. Wan, K. D. Duffee, B. M. Leonard, ChemCatChem 2015, 7 $3911-3915$.

[12] E. J. Popczun, J. R. McKone, C. G. Read, A. J. Biacchi, A. M. Wiltrout, N. S. Lewis, R. E. Schaak, J. Am. Chem. Soc. 2013, 135, 9267-9270.

[13] Y. Deng, Y. Zhou, Y. Yao, J. Wang, New J. Chem. 2013, 37, 4083-4088.
[14] a) D. Cai, B. Liu, D. Wang, Y. Liu, L. Wang, H. Li, Y. Wang, C. Wang, Q. Li, T. Wang, Electrochim. Acta 2014, 115, 358-363; b) W. Xiao, J. S. Chen, C. M. Li, R. Xu, X. W. Lou, Chem. Mater. 2010, 22, 746-754.

[15] C. Tang, W. Wang, A. Sun, C. Qi, D. Zhang, Z. Wu, D. Wang, ACS Catal. 2015, 5, 6956-6963.

[16] Y. Pan, Y. Liu, C. Liu, J. Power Sources 2015, 285, 169-177.

[17] J. F. Callejas, C. G. Read, C. W. Roske, N. S. Lewis, R. E. Schaak, Chem Mater. 2016, 28, 6017-6044.

[18] F. Bachhuber, J. von Appen, R. Dronskowski, P. Schmidt, T. Nilges, A. Pfitzner, R. Weihrich, Angew. Chem. Int. Ed. 2014, 53, 11629-11633, Angew. Chem. 2014, 126, 11813-11817.

[19] J. Kibsgaard, T. F. Jaramillo, Angew. Chem. Int. Ed. 2014, 53, $14433-$ 14437; Angew. Chem. 2014, 126, $14661-14665$.

[20] N. Perret, X. Wang, L. Delannoy, C. Potvin, C. Louis, M. A. Keane, J. Catal. 2012, 286, $172-183$.

[21] M. D. Porosoff, X. Yang, J. A. Boscoboinik, J. G. Chen, Angew. Chem. Int. Ed. 2014, 53, 6705-6709; Angew. Chem. 2014, 126, 6823-6827.

[22] A. P. Grosvenor, M. C. Biesinger, R. S. C. Smart, N. S. Mclntyre, Surf. Sci. 2006, 600, $1771-1779$.

[23] a) I. Abu, K. Smith, J. Catal. 2006, 241, 356-366; b) Z. Yao, J. Tong, X Qiao, J. Jiang, Y. Zhao, D. Liu, Y. Zhang, H. Wang, Dalton Trans. 2015, 44, $19383-19391$; c) R. Franke, T. Chassé, P. Streubel, A. Meisel, J. Electron Spectrosc. Relat. Phenom. 1991, 56, $381-388$

[24] L. S. Dake, J. Vac. Sci. Technol. A 1989, 7, 1634-1638.

[25] W. Gruenert, A. Y. Stakheev, R. Feldhaus, K. Anders, E. S. Shpiro, K. M. Minachev, J. Phys. Chem. 1991, 95, 1323-1328.

[26] Y. Li, C. Zhao, Chem. Mater. 2016, 28, 5659-5666.

[27] T. Chen, D. Liu, W. Lu, K. Wang, G. Du, A. M. Asiri, X. Sun, Anal. Chem 2016, 88, 7885-7889.

[28] a) S. J. Sawhill, K. A. Layman, D. R. Van Wyk, M. H. Engelhard, C. Wang, M. E. Bussell, J. Catal. 2005, 231, 300-313; b) C. Tang, L. Xie, K. Wang, G. Du, A. M. Asiri, Y. Luo, X. Sun, J. Mater. Chem. A 2016, 4, 12407-12410.

[29] A. B. Laursen, K. R. Patraju, M. J. Whitaker, M. Retuerto, T. Sarkar, N. Yao, K. V. Ramanujachary, M. Greenblatt, G. C. Dismukes, Energy Environ. Sci. 2015, 8, 1027-1034.

[30] a) Y. Pan, W. Hu, D. Liu, Y. Liu, C. Liu, J. Mater. Chem. A 2015, 3, 13087 13094; b) P. Jiang, Q. Liu, X. Sun, Nanoscale 2014, 6, 13440-13445.

[31] J. D. Benck, T. R. Hellstern, J. Kibsgaard, P. Chakthranont, T. F. Jaramillo, ACS Catal. 2014, 4, 3957-3971.

[32] T. Shinagawa, A. T. Garcia-Esparza, K. Takanabe, Sci. Rep. 2015, 5, $13801-$ 13822.

[33] J. F. Moulder, W. F. S. P. E. Sobol, K. D. Bomben, Handbook of X-Ray Photoelectron Spectroscopy, Perkin-Elmer Corp., Eden Prairie, MN, 1995.

[34] P. Kim, A. Johnson, C. W. Edmunds, M. Radosevich, F. Vogt, T. G. Rials, N. Labbé, Energy Fuels 2011, 25, 4693-4703.

[35] a) P. Gu, L. Bai, L. Gao, R. Brousseau, B. E. Conway, Electrochim. Acta 1992, 37, 2145-2154; b) W. A. Badawy, A. G. Gad-Allah, H. A. Abd ElRahman, M. M. Abouromia, Surf. Coat. Technol. 1986, 27, 187-196; c) M. Turner, G. E. Thompson, P. A. Brook, Corros. Sci. 1973, 13, 985-991.

Manuscript received: November 18, 2016

Revised: December 13, 2016

Accepted Article published: December 15, 2016

Final Article published: II, 0000 


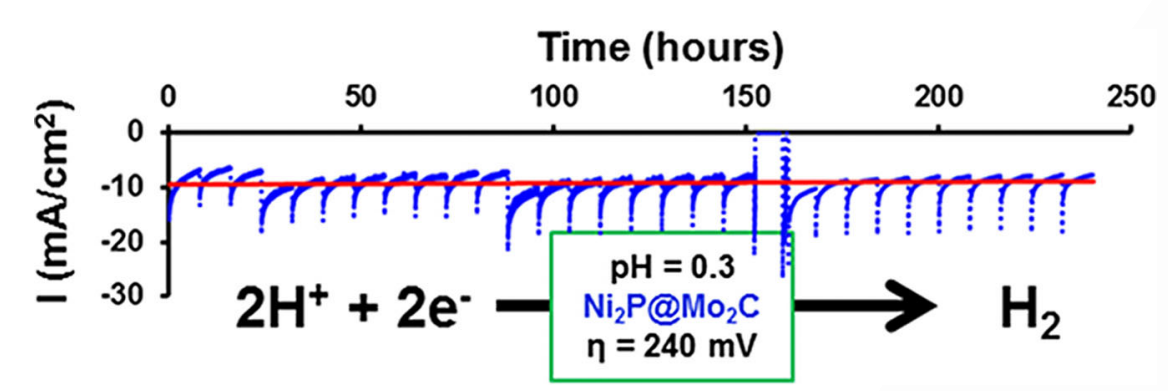

Carbide-phosphide composites with minimal lattice mismatch are prepared for energy conversion technologies. Nickel phosphide deposited on molybdenum carbide shows enhanced electrocatalytic activity and stability over
$240 \mathrm{~h}$ in acidic electrolyte. The synthesis is facile, highly reproducible, and has the potential to produce a new family of electrocatalysts based on earth-abundant elements.
Y. N. Regmi, ${ }^{*}$ A. Roy, G. A. Goenaga,

J. R. McBride, B. R. Rogers,

T. A. Zawodzinski, Jr., N. Labbé,

S. C. Chmely*

口- $\mathbf{n}$

Electrocatalytic Activity and Stability Enhancement through Preferential Deposition of Phosphide on Carbide

,

Carbide/phosphide \#composites w/ small lattice mismatch for energy conversion technologies @UTKnoxville @VanderbiltU SPACE RESERVED FOR IMAGE AND LINK

\begin{abstract}
Share your work on social media! ChemCatChem has added Twitter as a means to promote your article. Twitter is an online microblogging service that enables its users to send and read text-based messages of up to 140 characters, known as "tweets". Please check the pre-written tweet in the galley proofs for accuracy. Should you or your institute have a Twitter account, please let us know the appropriate username (i.e., @accountname), and we will do our best to include this information in the tweet. This tweet will be posted to the journal's Twitter account @ChemCatChem (follow us!) upon online publication of your article, and we recommended you to repost ("retweet") it to alert other researchers about your publication.
\end{abstract}

Please check that the ORCID identifiers listed below are correct. We encourage all authors to provide an ORCID identifier for each coauthor. ORCID is a registry that provides researchers with a unique digital identifier. Some funding agencies recommend or even require the inclusion of ORCID IDs in all published articles, and authors should consult their funding agency guidelines for details. Registration is easy and free; for further information, see http://orcid.org/.

Yagya N. Regmi

Asa Roy

Gabriel A. Goenaga

James R. McBride

B. R. Rogers

Thomas A. Zawodzinski, Jr.

Nicole Labbé

Stephen C. Chmely http://orcid.org/0000-0002-2637-9974 